\title{
Study on Parameter Boundary of the 2nd District of Shengtuo Oilfield Reservoir with Polymer Flooding
}

\author{
Xiaoyu Liu ${ }^{1}$, Da Gao ${ }^{1,2}$, Xuejiao $\mathrm{Lu}^{1,3}$, Jian Hou ${ }^{1, \text { a, * }}$ \\ ${ }^{1}$ School of Petroleum Engineering, China University of Petroleum, Qingdao, China \\ 2 Zhanjiang Branch of China National Offshore Oil Corporation, Zhanjiang, China \\ ${ }^{3}$ PetroChina Changqing Oilfield Company, Xian, China \\ *, a houjian@upc.edu.cn
}

Keywords: oil incremental investments, formation water salinity boundary.

\begin{abstract}
The research method of studying on parameter boundary of reservoir with polymer flooding has been established, using numerical simulation method combined with dynamic economic evaluation method. Based on Sha two 1-2 units of Shengtuo second area, the numerical simulation model is built and the influence of different reservoir parameters on polymer flooding is performed. Then the standard plates of various parameter boundaries for polymer flooding have been drawn under different oil prices and different oil incremental investments. Referring to the plate, the parameter boundaries for reservoir applied with the new type of heat resistance and salt tolerance polymer have been obtained. These parameter boundaries include: formation water salinity boundary, formation water calcium and magnesium ion content boundary, reservoir temperature boundary and oil viscosity boundary. The establishment of these parameter boundaries can be a guidance to dynamically facilitate the economic development of high temperature and high salinity reservoir with polymer flooding under consideration of oil price volatility.
\end{abstract}

\section{Introduction}

The application of polymer flooding has come into the stage of industrial application, and gradually developed into a quite mature technology to improve oil recovery [1-3]. The application of polymer flooding has been gradually carried out into some reservoirs which have relatively better reservoir condition. High temperature and high salinity reservoirs are quite common in Shengli Oilfield [4,5], which are rich in reserve but difficult in common polymer flooding. To adapt to the high temperature and high salt reservoir condition, the polymer flooding of high temperature and high salt reservoirs was carried out by a new type of temperature-resistant and salt-resistant polymer in Shengli Oilfield.

Although there are different criteria for polymer flooding [6,7], there is still lack of a targeted research about parameter boundaries of reservoir conditions in these temperature-resistant and salt-resistant polymer systems. Aiming at the characteristics of chemical flooding in high temperature and high salt reservoirs, this article studies the parameter boundaries of reservoir conditions which have severe influences in the development of high temperature and high salt reservoirs by polymer flooding and can provide basic theories for the realization of the scale and effective application of polymer flooding in high temperature and high salt reservoirs.

\section{The Establishment of Reservoir Numerical Simulation Model}

Sha two 1-2 units of Shengtuo second area is the pilot test area for the polymer flooding in high temperature and high salt reservoirs [8], The temperature of this unit is $80^{\circ} \mathrm{C}$, the formation water salinity is $24000 \mathrm{mg} / \mathrm{L}$, the content of calcium and magnesium is $447 \mathrm{mg} / \mathrm{L}$, it is a typical example of high temperature and high salt reservoirs. This district is just fan-shaped overall with a flat regional structure inclining to the southwest from northeast, the dip of the top of the structure is about $6^{\circ}$, the 
dip of the waist part of the structure is about $3^{\circ}$, however which of the edge is only $1 \sim 2^{\circ}$, the depth of reservoir is $1820 \sim 2060 \mathrm{~m}$, the interface of oil and water is uniform in the whole reservoir. And the pilot test area is located in the south part of this district with a flat regional structure, the stratigraphic dip is about $3 \sim 4^{\circ}$, the top of the reservoir is about 1970 2010m.

Select several well groups from the center of pilot test area to establish the numerical model of polymer flooding, the grid setting of the model is $21 \times 21 \times 7$, well pattern of the model is made up of four-reverse-five-spot pattern well groups, which includes 4 injection wells, 9 production wells, the distance of adjacent injection well and production well is $212 \mathrm{~m}$, and the distance of adjacent two production wells is $300 \mathrm{~m}$, the sketch of this model is shown in the figure 1 .
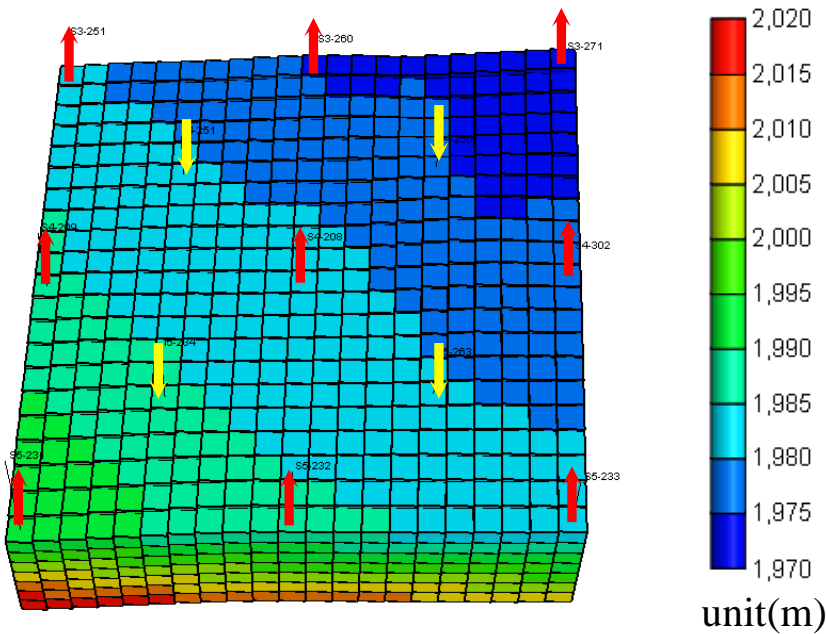

Figure 1. The model of basic case of polymer flooding

The oil-bearing area in basic model is $0.397 \mathrm{~km} 2$, the oil initially in place(OIIP) is $73 \times 104 \mathrm{t}$, the average effective thickness is $10 \mathrm{~m}$, the average porosity of the model is 0.3 , the average permeability is $3200 \mathrm{mD}$, the coefficient of variation in test area is 0.709 , the heterogeneity is relatively high. The viscosity of the oil in place is about $10 \sim 30 \mathrm{mPa} \cdot \mathrm{s}$.

The injection of polymer fluid is initiated just by the water cut reaches 0.97 , the injection of polymer fluid is supposed as two parts $(0.1 \mathrm{PV} \times 2400 \mathrm{mg} / \mathrm{L}$ polymer $+0.3 \mathrm{PV} \times 1900 \mathrm{mg} / \mathrm{L}$ polymer $)$, water is re-injected after the injection volume of polymer fluid reaches $0.4 \mathrm{PV}$. the water cut declines to $84.1 \%$, the final recovery factor reaches $44.7 \%$ which is $6.7 \%$ higher than the totally water flood.

\section{The Research of Influence Factors in Polymer Flooding}

Study results show that the formation water salinity, the content of calcium and magnesium, the temperature of reservoir and the oil viscosity exert great influence on the development efficiency of high temperature and high salt reservoirs flooded by polymer [9]. This research established the screening index parameters of high temperature and high salt reservoirs including formation water salinity, the content of calcium and magnesium, the temperature of reservoir and the oil viscosity.

Figure 2(a)shows the influence of formation water salinity on enhanced oil recovery of polymer flooding. It can be seen from the figure that a higher level of formation water salinity leads to a lower enhanced oil recovery of polymer flooding. The reason is that the carboxyl on polymer chain and the cation in inorganic salt can form the ion pairs, which weaken the electrostatic repulsion between polymer coils. As a consequence of that, polymer chains tend to curled in solution instead of extension, the effective volume of molecules reduces, resulting in a decline of the solution viscosity. In addition, with the increasing of formation water salinity, the adsorption capacity of polymer on rock surface increases, resulting in a decrease of effective polymer in solution which finally leads to the drop in viscosity. A higher value in formation water salinity leads to a greater drop in solution viscosity and the enhanced oil recovery also decreases.

The mechanism of calcium and magnesium influencing on polymer solution is the same as that of salinity, and the influence of calcium and magnesium is more significant than that of salinity 
(monovalent ions). The figure of enhanced oil recovery under the influence of different calcium and magnesium content is showed in 2(b).

Figure 2(c) shows the influence of reservoir temperature on enhanced oil recovery by polymer flooding. As the reservoir temperature increases, the enhanced oil recovery by polymer flooding decreases. The reason is that degradation reaction of polymer accelerates under high temperature, the viscosity of polymer solution decreases as the temperature increases, leading to a reduction in the function of polymer.

Oil viscosity is an important factor which influences the oil recovery by water flooding, it is also a parameter which influences the enhanced oil recovery by polymer flooding. The enhanced oil recovery by polymer flooding under different oil viscosities is showed in figure 2(d). As the underground oil viscosity increases, enhanced oil recovery of polymer flooding also increases. The reason is that the mechanism of polymer flooding is adjusting mobility ratio, extending swept volume. When the oil viscosity reaches at a relatively mid-high level, the effect of polymer flooding is the most obvious. However, when the oil viscosity continues to increase exceeding that range, the enhanced oil recovery begins to drop. That is due to the limitation of the effect polymer flooding exerts on mobility ratio.

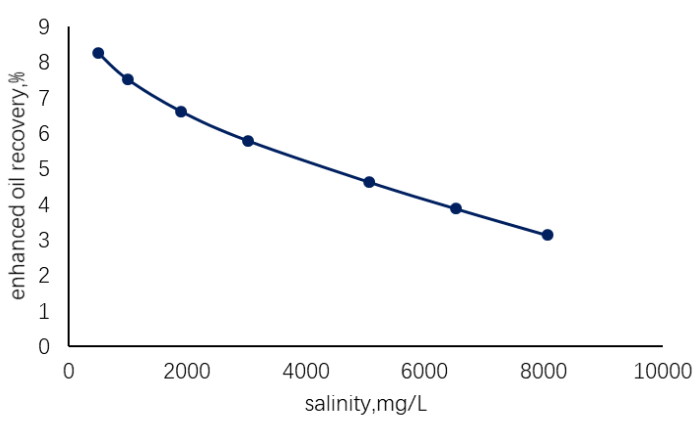

(a) formation water salinity

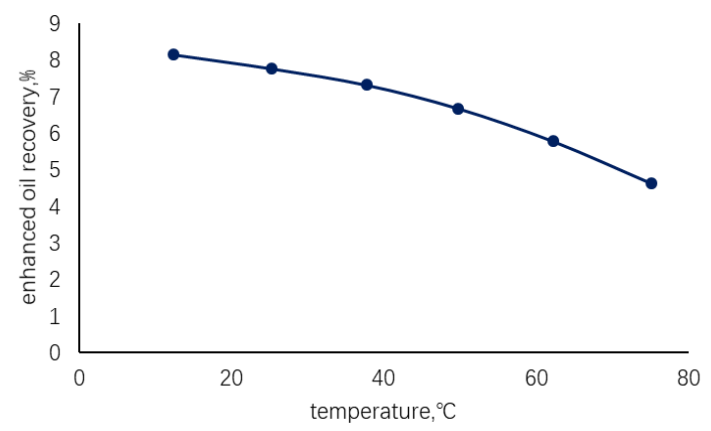

(c) reservoir temperature

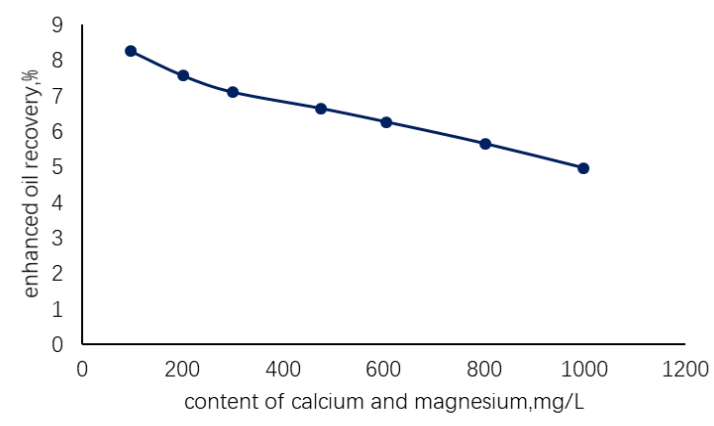

(b) content of calcium and magnesium

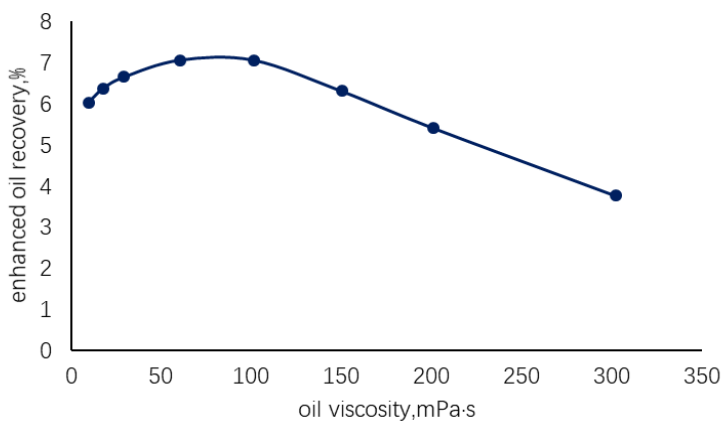

(d) underground oil viscosity

Figure 2. influence of reservoir parameters on the effect of polymer flooding

\section{The Method of Determining Parameter Boundaries in Reservoirs Using Polymer Flooding}

Combining the economy evaluation method, put forward the determining method of parameter boundaries of reservoir conditions in reservoirs which is flooded by polymer fluid [10], basic routine is: Using the method of numerical simulation to get influence rule of different reservoir parameters on polymer flooding performance. And then using the method of curve regression to get the relation of enhanced oil recovery and reservoir parameters. Combining the economy evaluation formula, the value of a parameter when the incremental cumulative net present value equals to 0 is the exact boundary to this parameter. With this method, the boundaries of different parameters (formation water salinity, the content of calcium and magnesium, the temperature of reservoir and the oil viscosity) when the polymer flooding is operated economically can be inferred.

The incremental cumulative net present value equals to 0 means that the economic value of which the cumulative production makes due to the increment which polymer flooding makes overpass that 
of water flooding. The expression using economy evaluation method to calculate the incremental cumulative net present value of polymer flooding is showed below:

$$
\gamma_{N P V}=\sum_{i=1}^{t}\left\{Q_{o i} P_{o} \alpha-\left[Q_{o i} C_{m}+Q_{p i} P_{p}+\left(R_{s}+R P_{o}\right) Q_{o i} \alpha\right]\right\} \times\left(1+i_{c}\right)^{-i}-n I_{s}
$$

In this expression, $\gamma_{N P V}$ —incremental cumulative net present value, yuan(¥); Qoi-enhanced oil per year, $\mathrm{t}$; Po-oil price, yuan/t; $\alpha$ - oil commodity rate, \%; $\mathrm{Cm}$-operating cost per ton of enhanced oil, yuan/t; Qpi - the injection of polymer per year, $\mathrm{t}$; $\mathrm{Pp}$ - the price of polymer, yuan/t; $\mathrm{R}$-composite tax rate, \%; Rs - resource tax, yuan/t; $\mathrm{n}$ - number of wells in the whole model; Is - incremental investment cost per well, yuan/well; $\mathrm{i}$ - simulation time, a (i=1....t); ic - benchmark yield, \%;

When $\gamma_{N P V}=0$, the corresponding oil production is the cumulative enhanced oil production at economic limit:

$$
Q_{o e}=\frac{n I_{s}+\sum_{i=1}^{t}\left(Q_{p i} P_{p}\right)\left(1+i_{c}\right)^{-i}}{\sum_{i=1}^{t}\left[\alpha(1-R) P_{o} r_{o}-r_{o}\left(C_{m}+R_{s}\right)\right]\left(1+i_{c}\right)^{-i}}
$$

The annual enhanced oil production is defined as:

$Q_{o i}=r_{o} Q_{o e}$

In this expression, ro - the ratio of annual enhanced oil production to the total enhanced oil production, \%( $\left.\sum r_{o}=1\right)$; Qoe-cumulative enhanced oil production at economic limit, t;

Combining the expression (2), the enhanced oil recovery factor of polymer flooding at economic limit can be inferred as below:

$$
R_{o e}=\frac{n I_{s}+\sum_{i=1}^{t}\left(Q_{p i} P_{p}\right)\left(1+i_{c}\right)^{-i}}{N \sum_{i=1}^{t}\left[\alpha(1-R) P_{o} r_{o}-r_{o}\left(C_{m}+R_{s}\right)\right]\left(1+i_{c}\right)^{-i}}
$$

The enhanced oil recovery factor of polymer flooding at economic limit is defined as:

$R_{o e}=\frac{Q_{o e}}{N}$

In this expression, Roe-enhanced oil recovery factor of polymer flooding at economic limit, \%; $\mathrm{N}$ - oil initially in place(OIIP), $\mathrm{t}$;

It can be seen from the expression that the production time period of polymer flooding, the ratio of annual enhanced oil production to the total enhanced oil production and the annual injection of polymer should be confirmed when calculating the enhanced oil recovery factor of polymer flooding at economic limit. annual injection of polymer can be determined by development plan. Production time period and enhanced oil ratio only have little variability under certain effective thickness and well distance. By the method of numerical simulation, exact production time period and enhanced oil ratio can be determined, then the enhanced oil recovery factor of polymer flooding at economic limit can be calculated.

\section{The Establishment of Standard Plates of Various Parameter Boundaries for Polymer Flooding}

Combining the field applications, investment cost of polymer flooding is available. The data of investment cost is showed in table 1 . The plates of enhanced oil recovery at economy limitation for polymer flooding under different oil prices and different oil incremental investments can be made by combining the expression (3) with simulation results and investment cost of polymer flooding as figure 3 showed. While the production well incremental investment is $100 \times 104 y u a n$ per well and the oil price is 2000yuan/t, the enhanced oil recovery at economy limitation for polymer flooding is $4.74 \%$. However, while the oil price is $3000 y u a n / t$, the enhanced oil recovery at economy limitation 
for polymer flooding is $2.5 \%$. It can be inferred that the enhanced oil recovery at economy limitation for polymer flooding is sensitive to oil price.

The process of determining the parameter boundaries for polymer flooding can be divided into two steps: (1)Fit the curve of different reservoir parameters and enhanced oil recovery of polymer flooding; (2) Calculate the parameter boundaries of different enhanced oil recovery at economy limitation based on the plates of enhanced oil recovery at economy limitation for polymer flooding to get the standard plates of various parameter boundaries for specific reservoirs. Take formation water salinity for example, as figure 2(a) shows, with the increasing of salinity the effect of polymer flooding becomes worse. Use quadratic polynomial to fit the curve of enhanced oil recovery by polymer flooding under different salinities. And then, calculate formation water salinity boundaries of specific enhanced oil recovery at economy limitation according to figure 3 . Finally the plate of formation water salinity boundary under different oil prices and different production incremental investments is completed as figure 4. Using similar method above, the plate of boundary of calcium and magnesium content(figure 5) and the plate of reservoir temperature boundary(figure 6) can also be made. According to the corresponding articles, the heat stability of polymer solution drops dramatically while the temperature of solution is over $93^{\circ} \mathrm{C}[11,12]$. So the temperature limitation of polymer flooding is $93^{\circ} \mathrm{C}$.

Table 1. investment cost of polymer flooding.

\begin{tabular}{cccccc}
\hline parameter & unit & value & parameter & unit & value \\
\hline Oil initially in place, $N$ & $10^{4} \mathrm{t}$ & 73.1 & the price of polymer, $P_{p}$ & $10^{4}$ yuan/t & 2.0 \\
Number of wells, $n$ & & 8 & resource tax, $R_{s}$ & yuan/t & 14 \\
Production incremental investment, $I_{s}$ & $10^{4}$ yuan/well & 100 & composite tax rate, $R$ & $\%$ & 14 \\
operating cost per ton of enhanced oil, $C_{m}$ & yuan/t & 800 & benchmark yield, $i_{c}$ & $\%$ & 12 \\
oil commodity rate, $\alpha$ & $\%$ & 97 & & \\
\hline
\end{tabular}

While the viscosity of oil is over $100 \mathrm{mPa} \cdot \mathrm{s}$, with the increasing of oil viscosity the enhanced oil recovery of polymer flooding decreases. Use the method of multiple regression to fit the descending section of enhanced oil recovery-oil viscosity curve. According to figure 2(d), the viscosity of oil has a linear relationship with the enhanced oil recovery. So the linear equation can be used in the fitting of this curve. And then, the plate of oil viscosity boundary for polymer flooding under different oil prices and different production incremental investments can be made as figure 7 .

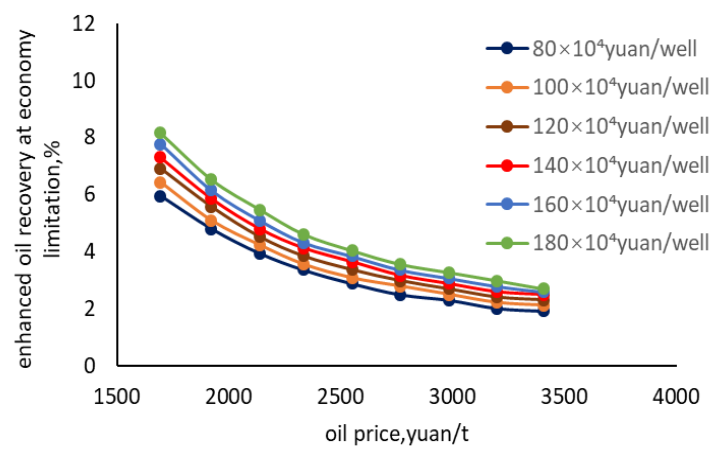

Figure 3. enhanced oil recovery at economy limitation

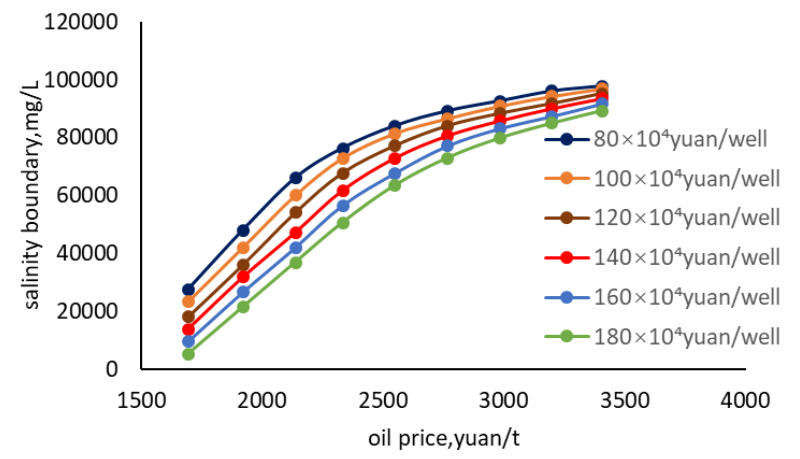

Figure 4. salinity boundary 

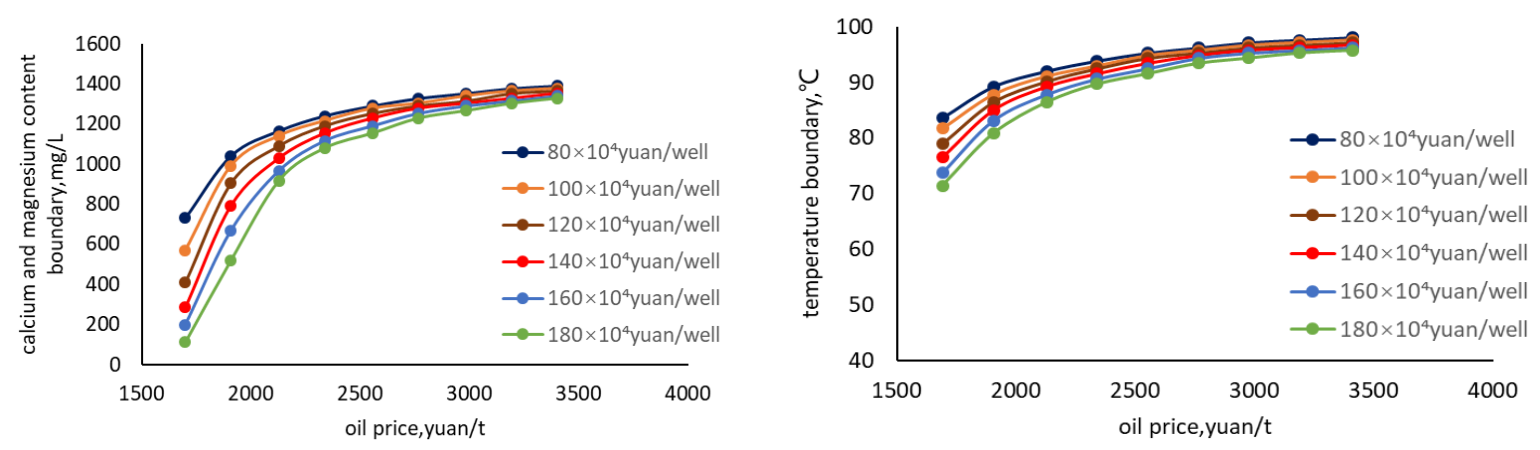

Figure 5. calcium and magnesium content boundary Figure 6. reservoir temperature boundary

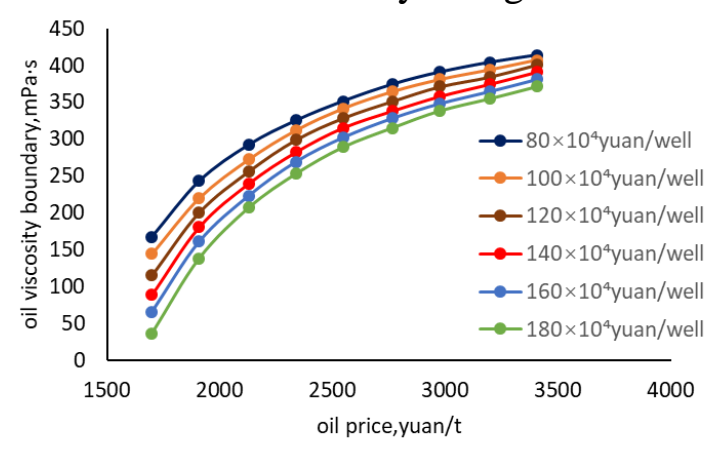

Figure 7. oil viscosity boundary

\section{Conclusion}

(1) The screening index parameters under consideration of oil price volatility is determined by sensitivity analysis of influencing factors in polymer flooding. Screening index parameters include formation water salinity, the content of calcium and magnesium, the temperature of reservoir and the underground oil viscosity.

(2) The criteria of reservoirs for polymer flooding is variation due to the volatility of oil price, therefore the plates can be used to determine the criteria of reservoir conditions more reasonably as the oil price changes.

\section{Acknowledgments}

This work was financially supported by National Science and Technology Major Project(2016ZX05011-003).

\section{References}

[1]. Shen P P,Yuan S Y, Han D, etal. Oil field development strategy study and potentiality evaluation of EOR for onshore oil fields in China[J]. Acta Petrolei Sinica, 2001, 22(1): 45-48.

[2]. Niu J G. Practices and understanding of polymer flooding enhanced oil recovery technique in Daqing Oilfield[J]. Petroleum Geology \& Oilfield Development in Daqing, 2004, 23(5): 91-93.

[3]. Li Z Q. Industrial test of polymer flooding in superhigh water cut stage of central No. 1 Block, Gudao Oilfield[J]. Petroleum Exploration and Development, 2004, 31(2): 119-121.

[4]. Wei C H. Field test of organic cross-linked polymer flooding in high temperature and high salinity oil reservoirs of Shengtuo Oilfield[J]. Petroleum Geology and Recovery Efficiency, 2007, 14(5): 69-71. 
[5]. Zhang X Y. Field test of ultra-high molecular weight hydrophobic associative polymer flooding in high temperature and high salinity oil reservoirs[J]. Petroleum Geology and Engineering, 2012, 26(6): 122-124.

[6]. Taber J. J., Martin F. D., Seright R. S. EOR screening criteria revisited - Part 1: Introduction to screening criteria and enhanced recovery field projects[J]. SPE Reservoir Engineering, 1997, 8: 189-198.

[7]. Taber J. J., Martin F. D., Seright R. S. EOR screening criteria revisited - Part 2: Applications and impact of oil prices[J]. SPE Reservoir Engineering, 1997, 8: 199-205.

[8]. Wei C H. Pilot testing of polymer flooding in Shengtuo Oilfield with high temperature and high salinity reservoir[J]. Drilling \& Production Technology, 2008, 31(2): 113-115.

[9]. Gao D. Effect evaluation and reservoir adaptability of chemical flooding for high temperature and high salinity reservoir[D]. China University of Petroleum, 2010.

[10]. Gao D, Hou J, Sun J F, etal. Economic and technical limit of steam soak in horizontal well of heavy oil reservoir[J]. Petroleum Geology and Recovery Efficiency, 2011, 18(1): 92-96.

[11]. Ryles R. G. Chemical stability limits of water-soluble polymers used in oil recovery processes[J]. SPE Reservoir Engineering, 1988, 3(1): 23-34.

[12]. Abou-Kassem J. H. Screening of oil reservoirs for selecting candidates of polymer injection[J]. Energy Sources, 1999, 21(1): 5-15. 